\title{
Journal of Comparative Social Work
}

\section{Call for papers}

\section{Special issue on 'Welfare in Latin America and the Nordic countries'}

The Journal of Comparative Social Work invites you to submit a paper to a special issue on the following topic: "Welfare in Latin America and the Nordic countries." The issue will appear as Vol. 14, No. 1 (2019).

Special issue editors: Morten Tønnessen (University of Stavanger), Angela Peña (University of Havana), Sarah Hean (University of Stavanger) and Siv Oltedal (University of Stavanger)

Welfare issues and social problems are contextual research topics that may be studied within or between different welfare regimes. Research themes include social work with families, child welfare, restorative justice within the criminal justice system, mental health, unemployment issues and interagency/interprofessional collaboration and service integration.

Societies face social change for a variety of reasons, including demographic shifts, economic growth or decline and political and cultural developments. Being concerned with facilitating social progress, social workers around the world have to deal with the social change that occurs in the societies in which they are engaged.

This special issue will focus on welfare and social change in Latin America and the Nordic countries. In recent history, several Latin American and Nordic countries have undergone considerable, and in some cases unprecedented, social change. How have welfare regimes and social change affected the conditions for doing social work? What challenges are social workers experiencing, and how are they being met? In light of ongoing and expected social change, the sustainability of different welfare regimes is up for discussion.

Contributions to the special issue should address one or more of the questions indicated above. They may apply a historical, contemporary or future-oriented perspective, and may have a local, national or international focus.

Articles can have a maximum length of 7,000 words, and should meet the standards of original scholarly research. They will be anonymized and reviewed through a double blind peer review process. For further author guidelines and more information about the journal, see http://journal.uia.no/index.php/JCSW?page=about.

All articles in this special issue of Journal of Comparative Social Work will be published with an English, as well as Spanish abstract.

Please send submissions to: morten.tonnessen@uis.no

Deadlines:

Submission of English language abstract: $25^{\text {th }}$ of June 2018.

Submission of full paper (in English): $1^{\text {st }}$ of November 2018 